\section{Dr. Granel, et al reply}

\section{To the Editor:}

We thank Nair and Karumanchery for their comments ${ }^{1}$ on our case report ${ }^{2}$. In our observation, cardiac magnetic resonance imaging (MRI) was crucial and sufficient for the diagnosis of myocarditis, according to the International Consensus Group on Cardiovascular Magnetic Resonance Diagnosis of Myocarditis, which considers cardiac MRI a noninvasive primary tool to diagnose myocarditis ${ }^{3}$. However, as Nair and Karumanchery recall, cardiac MRI does not provide an etiological diagnosis of myocarditis, and has no specificity for infectious diseases.

Although endomyocardial biopsy is classically considered the gold standard to certify myocarditis, it is not recommended in the absence of heart failure owing to the unfavorable benefit/risk balance ${ }^{4}$. Indeed, the hazards associated with endomyocardial biopsy have been estimated as up to $6 \% 5$ and included inadvertent pneumothorax, puncture of central arteries, arrhythmia and conduction abnormalities, liver puncture, damage to the tricuspid valve, and ventricular perforation with pericardial tamponade, all potentially life-threatening. Further, the value of endomyocardial biopsy may be limited by its low sensitivity, depending on the quality of the samples, the risk in taking a sample from an uninvolved area, as biopsies are commonly performed in the apical portion of the right ventricular septum, and its poor correlation and predictive value for heart failure. For all these reasons, the accuracy of the standard Dallas pathological criteria is currently controversial ${ }^{6}$.

We agree with the comment that diagnosis of myocarditis is a real challenge in a patient with chest pain and ischemia-like echocardiography changes. Coronary angiography is usually performed to eliminate acute myocardial infarction (MI). However, in our case (as noted in the text), normal level of cardiac troponin I and left ventricular function were not in favor of acute MI. Moreover, early first-pass perfusion and delayed-enhancement MRI sequences allow differentiation of myocarditis from acute $\mathrm{MI}^{7}$. In contrast to acute MI, the pattern in myocarditis includes focal or diffuse nonsegmental nonsubendocardial delayed-enhancement, which predominates in the inferolateral location with no early defect ${ }^{7}$.

Thus, physicians should investigate such cardiac complications in giant cell arteritis by taking the patient's safety and the adequacy of diagnostic procedures into account.
BRIGITTE GRANEL, MD; AURÉLIE DAUMAS, MD; PASCAL ROSSI, MD, Service de Médecine Interne, Hôpital Nord, Assistance Publique-Hôpitaux de Marseille; ALEXIS JACQUIER, MD, Service d’Imagerie Médicale, Hôpital de la Timone, Assistance Publique-Hôpitaux de Marseille, Marseille, France. Address correspondence to Dr. B. Granel, Service de Médecine Interne, Hôpital Nord, Chemin des Bourrely, 13915 Marseille cedex 15, France.

E-mail: bgranel@ap-hm.fr

\section{REFERENCES}

1. Nair JR, Karumanchery R. Myopericarditis and giant cell arteritis in the elderly [letter]. J Rheumatol 2013;40:95-6.

2. Daumas A, Rossi P, Jacquier A, Granel B. Myopericarditis revealing giant cell arteritis in the elderly [letter]. J Rheumatol 2012;39:665-7.

3. Friedrich MG, Sechtem U, Schulz-Menger J, Holmvang G, Alakija $\mathrm{P}$, Cooper LT, et al; International Consensus Group on Cardiovascular Magnetic Resonance in Myocarditis. Cardiovascular magnetic resonance in myocarditis: A JACC White Paper. J Am Coll Cardiol 2009;53:1475-87.

4. Cooper LT, Baughman KL, Feldman AM, Frustaci A, Jessup M, Kuhl U, et al. The role of endomyocardial biopsy in the management of cardiovascular disease: A scientific statement from the American Heart Association, the American College of Cardiology, and the European Society of Cardiology. Circulation 2007;116:2216-33.

5. Deckers JW, Hare JM, Baughman KL. Complications of transvenous right ventricular endomyocardial biopsy in adult patients with cardiomyopathy: A seven-year survey of 546 consecutive diagnostic procedures in a tertiary referral center. J Am Coll Cardiol 1992;19:43-7.

6. Cooper LT. Myocarditis. N Engl J Med 2009;360:1526-38.

7. Laissy JP, Hyafil F, Feldman LJ, Juliard JM, Schouman-Claeys E, Steg PG, et al. Differentiating acute myocardial infarction from myocarditis: Diagnostic value of early- and delayed-perfusion cardiac MR imaging. Radiology 2005;237:75-82.

J Rheumatol 2013;40:1; doi:10.3899/jrheum.121155 